\title{
Two new sequence spaces generated by the composition of $m$ th order generalized difference matrix and lambda matrix
}

\author{
Mustafa Cemil Bişgin* and Abdulcabbar Sönmez
}

\section{"Correspondence:}

mbisgin@erciyes.edu.tr Department of Mathematics,

Faculty of Science, Erciyes

University, Talas Street,

Melikgazi/Kayseri, 38039, Turkey

\begin{abstract}
In this work, we introduce two sequence spaces $c_{0}^{\lambda}\left(G^{m}\right)$ and $c^{\lambda}\left(G^{m}\right)$ generated by the composition of $m$ th order generalized difference matrix and lambda matrix and define an isomorphism between new sequence spaces and classical sequence spaces. Afterward, we investigate inclusion relations and obtain the Schauder basis of those spaces. Furthermore, we determine their $\alpha-, \beta$ - and $\gamma$-duals. Lastly, we characterize some matrix classes related to those spaces.
\end{abstract}

MSC: 40C05; 40H05; 46B45

Keywords: matrix transformations; matrix domain; Schauder basis; $\alpha$-, $\beta$ - and $\gamma$-duals; matrix classes

\section{Introduction}

The family of all real (or complex) valued sequences is denoted by $w . w$ is a vector space under point-wise addition and scalar multiplication. Any vector subspace of $w$ is called a sequence space. In the literature, the classical sequence spaces are symbolized with $\ell_{\infty}$, $c_{0}, c$ and $\ell_{p}$ which are called all bounded, null, convergent and absolutely $p$-summable sequence spaces, respectively, where $1 \leq p<\infty$.

A sequence space $\mathrm{X}$ with a linear topology is called a $K$-space provided each of the maps $p_{i}: X \rightarrow \mathbb{C}$ defined by $p_{i}(x)=x_{i}$ is continuous for all $i \in \mathbb{N}$. It is assumed that $w$ is always endowed with its locally convex topology generated by the sequence $\left\{p_{n}\right\}_{n=0}^{\infty}$ of semi-norms on $w$, where $p_{n}(x)=\left|x_{n}\right|, n=0,1,2, \ldots$ A $K$-space $X$ is called an $F K$-space provided $X$ is a complete linear metric space. An $F K$-space whose topology is normable is called a $B K$-space [1].

The classical sequence spaces $\ell_{\infty}, c_{0}$ and $c$ are $B K$-spaces with their usual sup-norm defined by $\|x\|_{\infty}=\sup _{k \in \mathbb{N}}\left|x_{k}\right|$ and $\ell_{p}$ is a $B K$-space with its $\ell_{p}$-norm defined by

$$
\|x\|_{\ell_{p}}=\left(\sum_{k=0}^{\infty}\left|x_{k}\right|^{p}\right)^{\frac{1}{p}},
$$

where $p \in[1, \infty)[2]$.

\section{严 Springer}

O2014 Bişgin and Sönmez; licensee Springer. This is an Open Access article distributed under the terms of the Creative Commons Attribution License (http://creativecommons.org/licenses/by/2.0), which permits unrestricted use, distribution, and reproduction in any medium, provided the original work is properly cited. 
Given an infinite matrix $A=\left(a_{n k}\right)$ with $a_{n k} \in \mathbb{C}$, for all $n, k \in \mathbb{N}$ and a sequence $x \in w$, the $A$-transform of $x$ is defined by

$$
(A x)_{n}=\sum_{k=0}^{\infty} a_{n k} x_{k}
$$

and is assumed to be convergent for all $n \in \mathbb{N}$ [3]. For using simple notations here and in what follows, the summation without limits runs from 0 to $\infty$. If $x \in X$ implies that $A x \in Y$, then we say that $A$ defines a matrix mapping from $X$ into $Y$ and denote it by $A: X \longrightarrow Y$. By using the notation $(X: Y)$, we mean the class of all infinite matrices $A$ such that $A: X \longrightarrow Y$.

For an arbitrary sequence space $X, X_{A}$ is called the domain of an infinite matrix $A$ and is defined by

$$
X_{A}=\left\{x=\left(x_{k}\right) \in w: A x \in X\right\}
$$

which is also a sequence space. By $b s$ and $c s$ we denote the spaces of all bounded and convergent series, and define them by means of the matrix domain of the summation matrix $S=\left(s_{n k}\right)$ such that $b s=\left(\ell_{\infty}\right)_{S}$ and $c s=c_{S}$, respectively, where $S=\left(s_{n k}\right)$ is defined by

$$
s_{n k}= \begin{cases}1, & 0 \leq k \leq n \\ 0, & k>n,\end{cases}
$$

which is a triangle matrix too. A matrix $A$ is called a triangle if $a_{n k}=0$ for $k>n$ and $a_{n n} \neq 0$ for all $n, k \in \mathbb{N}$. Moreover, a triangle matrix $A$ uniquely has an inverse $A^{-1}=B$ which is also a triangle matrix.

Unless stated otherwise, any term with negative subscript is assumed to be zero. The theory of matrix transformation was prompted by summability theory which was obtained by Cesàro, Riesz and others. The Cesàro mean of order one and the Riesz mean according to the sequence $p=\left(p_{n}\right)$ are defined by using the matrices $C=\left(c_{n k}\right)$ and $R^{p}=\left(r_{n k}^{p}\right)$ such that

$$
c_{n k}=\left\{\begin{array}{ll}
\frac{1}{n+1}, & 0 \leq k \leq n, \\
0, & k>n,
\end{array} \quad \text { and } \quad r_{n k}^{p}= \begin{cases}\frac{p_{k}}{P_{n},} & 0 \leq k \leq n \\
0, & k>n,\end{cases}\right.
$$

respectively, where $p_{0}>0, p_{n} \geq 0(n \geq 1)$ and $P_{n}=\sum_{k=0}^{n} p_{k}$.

Moreover, the theory of matrix transformation has been continued until nowadays. Many authors have constructed new sequence spaces by using matrix domain of infinite matrices. For example, $\left(\ell_{\infty}\right)_{N_{q}}$ and $c_{N_{q}}$ in [4], $a_{p}^{r}$ and $a_{\infty}^{r}$ in [5], $a_{0}^{r}$ and $a_{c}^{r}$ in [6], $Z\left(u, v ; \ell_{p}\right)$ in [7], $X_{p}$ and $X_{\infty}$ in [8], $e_{p}^{r}$ and $e_{\infty}^{r}$ in [9], $r_{\infty}^{t}, r_{0}^{t}$ and $r_{c}^{t}$ in [10], $r_{p}^{t}$ in [11], $e_{0}^{r}$ and $e_{c}^{r}$ in [12], $\tilde{c}$ and $\tilde{c}_{0}$ in [13]. Also, many authors introduced new sequence spaces by using especially difference matrices. For instance, $c_{0}(\Delta), c(\Delta)$ and $\ell_{\infty}(\Delta)$ in [14], $c_{0}\left(\Delta^{2}\right), c\left(\Delta^{2}\right)$ and $\ell_{\infty}\left(\Delta^{2}\right)$ in [15], $a_{0}^{r}(\Delta)$ and $a_{c}^{r}(\Delta)$ in [16], $c_{0}\left(\Delta^{m}\right), c\left(\Delta^{m}\right)$ and $\ell_{\infty}\left(\Delta^{m}\right)$ in [17], $\Delta c_{0}(p), \Delta c(p)$ and $\Delta \ell_{\infty}(p)$ in [18], $c_{0}\left(u: \Delta^{2}\right), c\left(u: \Delta^{2}\right)$ and $\ell_{\infty}\left(u: \Delta^{2}\right)$ in [19], $c_{0}(u, \Delta, p), c(u, \Delta, p)$ and $\ell_{\infty}(u, \Delta, p)$ in [20], $c_{0}\left(u, \Delta^{2}, p\right), c\left(u, \Delta^{2}, p\right)$ and $\ell_{\infty}\left(u, \Delta^{2}, p\right)$ in [21], $\Delta^{m} c_{0}(p), \Delta^{m} c(p)$ and 
$\Delta^{m} \ell_{\infty}(p)$ in [22], $r^{q}\left(p, B^{m}\right)$ in [23], $\hat{\ell}_{\infty}, \hat{c}, \hat{c}_{0}$ and $\hat{\ell}_{p}$ in [24], $c_{0}(B), c(B), \ell_{\infty}(B)$ and $\ell_{p}(B)$ in [25], $c_{0}\left(\Delta^{(m)}\right), c\left(\Delta^{(m)}\right)$ and $\ell_{\infty}\left(\Delta^{(m)}\right)$ in [26], $\Delta_{u}^{(m)} X$ in [27].

In this work, we introduce two sequence spaces $c_{0}^{\lambda}\left(G^{m}\right)$ and $c^{\lambda}\left(G^{m}\right)$ generated by the composition of $m$ th order generalized difference matrix and lambda matrix and define an isomorphism between new sequence spaces and classical sequence spaces. Afterward, we investigate inclusion relations and obtain the Schauder basis of those spaces. Furthermore, we determine their $\alpha$-, $\beta$ - and $\gamma$-duals. Lastly, we characterize some matrix classes related to those spaces.

\section{Two new sequence spaces}

In this section, we give some historical information and define the sequence spaces $c_{0}^{\lambda}\left(G^{m}\right)$ and $c^{\lambda}\left(G^{m}\right)$ generated by the composition of $m$ th order generalized difference matrix and lambda matrix. Moreover, we speak of some inclusion relations.

The idea of using the notion of $\lambda$-convergent was first motivated by Mursaleen and Noman in [28]. They defined the sequence spaces $c_{0}^{\lambda}, \ell_{\infty}^{\lambda}$ and $c^{\lambda}$ by means of the Lambda matrix $\Lambda=\left(\lambda_{n k}\right)$ such that

$$
\begin{aligned}
& c_{0}^{\lambda}=\left\{x=\left(x_{k}\right) \in w: \lim _{n \rightarrow \infty} \frac{1}{\lambda_{n}} \sum_{k=0}^{n}\left(\lambda_{k}-\lambda_{k-1}\right) x_{k}=0\right\}, \\
& c^{\lambda}=\left\{x=\left(x_{k}\right) \in w: \lim _{n \rightarrow \infty} \frac{1}{\lambda_{n}} \sum_{k=0}^{n}\left(\lambda_{k}-\lambda_{k-1}\right) x_{k} \text { exists }\right\}
\end{aligned}
$$

and

$$
\ell_{\infty}^{\lambda}=\left\{x=\left(x_{k}\right) \in w: \sup _{n \in \mathbb{N}}\left|\frac{1}{\lambda_{n}} \sum_{k=0}^{n}\left(\lambda_{k}-\lambda_{k-1}\right) x_{k}\right|<\infty\right\}
$$

where $\lambda=\left(\lambda_{k}\right)$ consists of positive reals such that

$$
0<\lambda_{0}<\lambda_{1}<\cdots \quad \text { and } \quad \lim _{k \rightarrow \infty} \lambda_{k}=\infty
$$

and the lambda matrix $\Lambda=\left(\lambda_{n k}\right)$ is defined by

$$
\lambda_{n k}= \begin{cases}\frac{\lambda_{k}-\lambda_{k-1}}{\lambda_{n}}, & 0 \leq k \leq n \\ 0, & k>n\end{cases}
$$

for all $k, n \in \mathbb{N}$. Here, we would like to touch on a point, if we take $\lambda_{n}=n+1$ and $\lambda_{n}=P_{n}$, for all $n \in \mathbb{N}$, we obtain the Cesàro mean of order one and the Riesz mean matrix, respectively. So, the $\Lambda=\left(\lambda_{n k}\right)$ matrix generalizes the $C=\left(c_{n k}\right)$ and $R^{p}=\left(r_{n k}^{p}\right)$ matrices.

Also, they improved their work by constructing the spaces $c_{0}^{\lambda}(\Delta)$ and $c^{\lambda}(\Delta)$ in [29]. The sequence spaces $c_{0}^{\lambda}(\Delta)$ and $c^{\lambda}(\Delta)$ are defined by

$$
c_{0}^{\lambda}(\Delta)=\left\{x=\left(x_{k}\right) \in w: \lim _{n \rightarrow \infty} \frac{1}{\lambda_{n}} \sum_{k=0}^{n}\left(\lambda_{k}-\lambda_{k-1}\right)\left(x_{k}-x_{k-1}\right)=0\right\}
$$


and

$$
c^{\lambda}(\Delta)=\left\{x=\left(x_{k}\right) \in w: \lim _{n \rightarrow \infty} \frac{1}{\lambda_{n}} \sum_{k=0}^{n}\left(\lambda_{k}-\lambda_{k-1}\right)\left(x_{k}-x_{k-1}\right) \text { exists }\right\}
$$

where $\Delta$ is a difference matrix.

Afterward, Sönmez and Başar defined the sequence spaces $c_{0}^{\lambda}(B)$ and $c^{\lambda}(B)$ in [30] and improved Mursaleen and Noman's work as follows:

$$
c_{0}^{\lambda}(B)=\left\{x=\left(x_{k}\right) \in w: \lim _{n \rightarrow \infty} \frac{1}{\lambda_{n}} \sum_{k=0}^{n}\left(\lambda_{k}-\lambda_{k-1}\right)\left(b_{1} x_{k}+b_{2} x_{k-1}\right)=0\right\}
$$

and

$$
c^{\lambda}(B)=\left\{x=\left(x_{k}\right) \in w: \lim _{n \rightarrow \infty} \frac{1}{\lambda_{n}} \sum_{k=0}^{n}\left(\lambda_{k}-\lambda_{k-1}\right)\left(b_{1} x_{k}+b_{2} x_{k-1}\right) \text { exists }\right\},
$$

where $B=B\left(b_{1}, b_{2}\right)$ is called a double band (generalized difference) matrix defined by

$$
b_{n k}= \begin{cases}b_{1}, & k=n \\ b_{2}, & k=n-1 \\ 0, & \text { otherwise }\end{cases}
$$

Let $r$ and $s$ be non-zero real numbers, then the $m$ th order generalized difference matrix $G^{m}(r, s)=\left(g_{n k}^{m}(r, s)\right)$ is defined by

$$
g_{n k}^{m}(r, s)= \begin{cases}\left(\begin{array}{c}
m-1 \\
n-k
\end{array}\right) r^{m-n+k-1} s^{n-k}, & \max \{0, n-m+1\} \leq k \leq n, \\
0, & \text { otherwise }\end{cases}
$$

for all $n, k \in \mathbb{N}$ and $m \in \mathbb{N}_{2}=\{2,3,4, \ldots\}$. We want to recall that $G^{2}(r, s)=B\left(b_{1}, b_{2}\right)$, $G^{3}(r, s)=B\left(b_{1}, b_{2}, b_{3}\right), G^{4}(r, s)=B\left(b_{1}, b_{2}, b_{3}, b_{4}\right), G^{5}(r, s)=B\left(b_{1}, b_{2}, b_{3}, b_{4}, b_{5}\right), \ldots$ where $B\left(b_{1}, b_{2}\right), B\left(b_{1}, b_{2}, b_{3}\right), B\left(b_{1}, b_{2}, b_{3}, b_{4}\right), B\left(b_{1}, b_{2}, b_{3}, b_{4}, b_{5}\right), \ldots$ are double band (that is, the generalized difference matrix), triple band, quadruple band, quinary band, ... matrix, respectively. Moreover, $G^{m}(1,-1)=\Delta^{m}, G^{2}(1,-1)=\Delta, G^{3}(1,-1)=\Delta^{2}$. So, our results obtained from the matrix domain of the $m$ th order generalized difference matrix $G^{m}$ are more general and more extensive than the results on the matrix domain of $B\left(b_{1}, b_{2}\right)$, $B\left(b_{1}, b_{2}, b_{3}\right), B\left(b_{1}, b_{2}, b_{3}, b_{4}\right), B\left(b_{1}, b_{2}, b_{3}, b_{4}, b_{5}\right), \ldots, \Delta^{m}, \Delta^{2}$ and $\Delta$.

By considering the definition of $m$ th order generalized difference matrix $G^{m}$, we define the sequence spaces $c_{0}^{\lambda}\left(G^{m}\right)$ and $c^{\lambda}\left(G^{m}\right)$ as follows:

$$
c_{0}^{\lambda}\left(G^{m}\right)=\left\{x=\left(x_{k}\right) \in w: \lim _{n \rightarrow \infty} \frac{1}{\lambda_{n}} \sum_{k=0}^{n}\left(\lambda_{k}-\lambda_{k-1}\right) \sum_{\vartheta=0}^{m-1}\left(\begin{array}{c}
m-1 \\
\vartheta
\end{array}\right) r^{m-\vartheta-1} s^{\vartheta} x_{k-\vartheta}=0\right\}
$$

and

$$
c^{\lambda}\left(G^{m}\right)=\left\{x=\left(x_{k}\right) \in w: \lim _{n \rightarrow \infty} \frac{1}{\lambda_{n}} \sum_{k=0}^{n}\left(\lambda_{k}-\lambda_{k-1}\right) \sum_{\vartheta=0}^{m-1}\left(\begin{array}{c}
m-1 \\
\vartheta
\end{array}\right) r^{m-\vartheta-1} s^{\vartheta} x_{k-\vartheta} \text { exists }\right\} .
$$


If we recall the notation of (1.2), the sequence spaces $c_{0}^{\lambda}\left(G^{m}\right)$ and $c^{\lambda}\left(G^{m}\right)$ can be redefined by the matrix domain of $G^{m}$ as follows:

$$
c_{0}^{\lambda}\left(G^{m}\right)=\left(c_{0}^{\lambda}\right)_{G^{m}} \quad \text { and } \quad c^{\lambda}\left(G^{m}\right)=c_{G^{m}}^{\lambda}
$$

Also, by constructing a triangle matrix $T^{m \lambda}=\left(t_{n k}^{m \lambda}\right)$ so that

$$
t_{n k}^{m \lambda}= \begin{cases}\frac{1}{\lambda_{n}} \sum_{\vartheta=0}^{m-1}\left(\begin{array}{c}
m-1 \\
\vartheta
\end{array}\right) r^{m-\vartheta-1} s^{\vartheta}\left(\lambda_{k+\vartheta}-\lambda_{k+\vartheta-1}\right), & k<n-m+2, \\
\frac{1}{\lambda_{n}} \sum_{\vartheta=1}^{m-1}\left(\begin{array}{c}
m-1 \\
\vartheta-1
\end{array}\right) r^{m-\vartheta} s^{\vartheta-1}\left(\lambda_{n-m+\vartheta+1}-\lambda_{n-m+\vartheta}\right), & k=n-m+2, \\
\frac{1}{\lambda_{n}} \sum_{\vartheta=2}^{m-1}\left(\begin{array}{c}
m-1 \\
\vartheta-2
\end{array}\right) r^{m-\vartheta+1} s^{\vartheta-2}\left(\lambda_{n-m+\vartheta+1}-\lambda_{n-m+\vartheta}\right), & k=n-m+3, \\
\vdots & \\
\frac{r^{m-1}\left(\lambda_{n-1}-\lambda_{n-2}\right)+(m-1) r^{m-2} s\left(\lambda_{n}-\lambda_{n-1}\right)}{\lambda_{n}}, & k=n-1, \\
\frac{r^{m-1}\left(\lambda_{n}-\lambda_{n-1}\right)}{\lambda_{n}}, & k=n, \\
0, & k>n\end{cases}
$$

for all $n, k \in \mathbb{N}$ and $m \in \mathbb{N}_{2}$, we rearrange the sequence spaces $c_{0}^{\lambda}\left(G^{m}\right)$ and $c^{\lambda}\left(G^{m}\right)$ by means of the $T^{m \lambda}=\left(t_{n k}^{m \lambda}\right)$ matrix as follows:

$$
c_{0}^{\lambda}\left(G^{m}\right)=\left(c_{0}\right)_{T^{m \lambda}} \quad \text { and } \quad c^{\lambda}\left(G^{m}\right)=c_{T^{m \lambda}} .
$$

So, for a given arbitrary sequence $x=\left(x_{k}\right)$, the $T^{m \lambda}$-transform of $x$ is denoted by

$$
y_{k}=\left(T^{m \lambda} x\right)_{k}=\frac{1}{\lambda_{k}} \sum_{j=0}^{k}\left(\lambda_{j}-\lambda_{j-1}\right) \sum_{\vartheta=0}^{m-1}\left(\begin{array}{c}
m-1 \\
\vartheta
\end{array}\right) r^{m-\vartheta-1} s^{\vartheta} x_{j-\vartheta}
$$

for all $k \in \mathbb{N}$, or, by using another representation, we can rewrite the sequence $y=\left(y_{k}\right)$ as follows:

$$
y_{k}=\frac{1}{\lambda_{k}} \sum_{j=0}^{k-m+1} \sum_{\vartheta=0}^{m-1}\left(\begin{array}{c}
m-1 \\
\vartheta
\end{array}\right) r^{m-\vartheta-1} s^{\vartheta}\left(\lambda_{j+\vartheta}-\lambda_{j+\vartheta-1}\right) x_{j}+\cdots+\frac{r^{m-1}\left(\lambda_{k}-\lambda_{k-1}\right)}{\lambda_{k}} x_{k}
$$

for all $k \in \mathbb{N}$.

Theorem 2.1 The sequence spaces $c_{0}^{\lambda}\left(G^{m}\right)$ and $c^{\lambda}\left(G^{m}\right)$ are BK-spaces according to their norms defined by

$$
\|x\|_{c_{0}^{\lambda}\left(G^{m}\right)}=\|x\|_{c^{\lambda}\left(G^{m}\right)}=\left\|\left(T^{m \lambda} x\right)_{n}\right\|_{\infty}=\sup _{n \in \mathbb{N}}\left|\left(T^{m \lambda} x\right)_{n}\right|
$$

Proof It is known that $c$ and $c_{0}$ are BK-spaces with their sup-norm [2]. Also (2.2) holds and $T^{m \lambda}=\left(t_{n k}^{m \lambda}\right)$ is a triangle matrix. If we consider these three facts and Theorem 4.3.12 of Wilansky [3], we conclude that $c_{0}^{\lambda}\left(G^{m}\right)$ and $c^{\lambda}\left(G^{m}\right)$ are $B K$-spaces. This step completes the proof.

Theorem 2.2 The sequence spaces $c_{0}^{\lambda}\left(G^{m}\right)$ and $c^{\lambda}\left(G^{m}\right)$ are linearly isomorphic to the sequence spaces $c_{0}$ and $c$, respectively. 
Proof To avoid the repetition of similar statements, we give the proof of the theorem for only the sequence space $c^{\lambda}\left(G^{m}\right)$. For the proof, the existence of a linear bijection between the spaces $c^{\lambda}\left(G^{m}\right)$ and $c$ should be shown. Let us define a transformation $L$ such that $L$ : $c^{\lambda}\left(G^{m}\right) \longrightarrow c, L(x)=T^{m \lambda} x$. Then it is clear that for all $x \in c^{\lambda}\left(G^{m}\right), L(x)=T^{m \lambda} x \in c$. Also, it is trivial that $L$ is a linear transformation and $x=0$ whenever $L(x)=0$. On account of this, $L$ is injective.

Furthermore, for a given sequence $y=\left(y_{k}\right) \in c$, we define the sequence $x=\left(x_{k}\right)$ as follows:

$$
x_{k}=\frac{1}{r^{m-1}} \sum_{j=0}^{k}\left(\begin{array}{c}
m+k-j-2 \\
m-2
\end{array}\right)\left(-\frac{s}{r}\right)^{k-j} \sum_{i=j-1}^{j}(-1)^{j-i} \frac{\lambda_{i}}{\lambda_{j}-\lambda_{j-1}} y_{i}
$$

for all $k \in \mathbb{N}$. Then, for every $n \in \mathbb{N}$, we obtain

$$
\sum_{\vartheta=0}^{m-1}\left(\begin{array}{c}
m-1 \\
\vartheta
\end{array}\right) r^{m-\vartheta-1} s^{\vartheta} x_{k-\vartheta}=\sum_{i=k-1}^{k}(-1)^{k-i} \frac{\lambda_{i}}{\lambda_{k}-\lambda_{k-1}} y_{i} .
$$

If we consider the equality above, for all $n \in \mathbb{N}$, we conclude that

$$
\begin{aligned}
\left(T^{m \lambda} x\right)_{n} & =\frac{1}{\lambda_{n}} \sum_{k=0}^{n}\left(\lambda_{k}-\lambda_{k-1}\right) \sum_{\vartheta=0}^{m-1}\left(\begin{array}{c}
m-1 \\
\vartheta
\end{array}\right) r^{m-\vartheta-1} s^{\vartheta} x_{k-\vartheta} \\
& =\frac{1}{\lambda_{n}} \sum_{k=0}^{n}\left(\lambda_{k}-\lambda_{k-1}\right) \sum_{i=k-1}^{k}(-1)^{k-i} \frac{\lambda_{i}}{\lambda_{k}-\lambda_{k-1}} y_{i} \\
& =\frac{1}{\lambda_{n}} \sum_{k=0}^{n} \sum_{i=k-1}^{k}(-1)^{k-i} \lambda_{i} y_{i} \\
& =y_{n} .
\end{aligned}
$$

So, $T^{m \lambda} x=y$ and since $y \in c$, we bring to a conclusion that $T^{m \lambda} x \in c$. Hence, we conclude that $x \in c^{\lambda}\left(G^{m}\right)$ and $L(x)=y$. Thus $L$ is surjective.

Furthermore, we have for every $x \in c^{\lambda}\left(G^{m}\right)$ that

$$
\|L(x)\|_{\infty}=\left\|T^{m \lambda} x\right\|_{\infty}=\|x\|_{c^{\lambda}\left(G^{m}\right)}
$$

So, $L$ is norm preserving. As a consequence, $L$ is a linear bijection. This step shows that the spaces $c^{\lambda}\left(G^{m}\right)$ and $c$ are linearly isomorphic, namely $c^{\lambda}\left(G^{m}\right) \cong c$.

Lemma 2.3 [28] The inclusions $c_{0} \subset c_{0}^{\lambda}$ and $c \subset c^{\lambda}$ hold.

Theorem 2.4 The inclusion $c_{0}^{\lambda}\left(G^{m}\right) \subset c^{\lambda}\left(G^{m}\right)$ strictly holds.

Proof It is well known that every null sequence is also convergent. So, the inclusion $c_{0}^{\lambda}\left(G^{m}\right) \subset c^{\lambda}\left(G^{m}\right)$ holds. Now we define a sequence $x=\left(x_{k}\right)$ such that

$$
x_{k}=\frac{1}{r^{m-1}} \sum_{j=0}^{k}\left(\begin{array}{c}
m+j-2 \\
m-2
\end{array}\right)\left(-\frac{s}{r}\right)^{j}
$$


for all $k \in \mathbb{N}$. Then we obtain by (2.3) that

$$
\left(T^{m \lambda} x\right)_{n}=\frac{1}{\lambda_{n}} \sum_{k=0}^{n}\left(\lambda_{k}-\lambda_{k-1}\right)=1
$$

for all $n \in \mathbb{N}$, which gives us that $T^{m \lambda} x=e$, where $e=(1,1, \ldots)$. Then $T^{m \lambda} x=e \in c \backslash c_{0}$, namely $x \in c^{\lambda}\left(G^{m}\right) \backslash c_{0}^{\lambda}\left(G^{m}\right)$. This shows that the inclusion $c_{0}^{\lambda}\left(G^{m}\right) \subset c^{\lambda}\left(G^{m}\right)$ strictly holds. This step completes the proof.

Theorem 2.5 If $r+s=0$, the inclusion $c \subset c_{0}^{\lambda}\left(G^{m}\right)$ is strict.

Proof It is clear that $\Delta x, \Delta^{2} x, \Delta^{3} x, \ldots, \Delta^{m} x \in c_{0}$ whenever $x \in c$. Assume that $r+s=0$ and $x \in c$. Then $G^{m} x=r^{m-1} \Delta^{m} x$ and because of $\Delta^{m} x \in c_{0}, G^{m} x \in c_{0}$. If we consider this fact and Lemma 2.3, we deduce that $G^{m} x \in c_{0}^{\lambda}$. This shows that $x \in c_{0}^{\lambda}\left(G^{m}\right)$. As a consequence, $c \subset c_{0}^{\lambda}\left(G^{m}\right)$ holds. Now we define a sequence $y=\left(y_{k}\right)$ such that $y_{k}=\ln k$ for all $k \in \mathbb{N}$ and $k>m$. Then it is obvious that $G^{m} y \in c_{0}$ but $y \notin c$. Because of $c_{0} \subset c_{0}^{\lambda}$, we conclude that $G^{m} y \in c_{0}^{\lambda}$ and thereby $y \in c_{0}^{\lambda}\left(G^{m}\right)$. This shows that $c \subset c_{0}^{\lambda}\left(G^{m}\right)$ strictly holds if $r+s=0$. This step completes the proof.

If we combine Theorem 2.4 and Theorem 2.5, we give the following result.

Corollary 2.6 If $r+s=0$, the inclusions $c_{0} \subset c_{0}^{\lambda}\left(G^{m}\right)$ and $c \subset c^{\lambda}\left(G^{m}\right)$ are strict.

Now we define two sequences $x=\left(x_{k}\right)$ and $y=\left(y_{k}\right)$ such that $x_{k}=\frac{k}{k+1}$ and $y_{k}=\sqrt{k+m}$ for all $k \in \mathbb{N}$ and $m \in \mathbb{N}_{2}$. Then we can see that $x \in \ell_{\infty}$ and $G^{m} x \in c_{0} \subset c_{0}^{\lambda}$, namely $x \in c_{0}^{\lambda}\left(G^{m}\right)$. Also, it is clear that $y \in c_{0}^{\lambda}\left(G^{m}\right) \backslash \ell_{\infty}$. These two facts give us the following corollary.

Corollary 2.7 The spaces $\ell_{\infty}$ and $c_{0}^{\lambda}\left(G^{m}\right)$ overlap but the space $\ell_{\infty}$ does not include the space $c_{0}^{\lambda}\left(G^{m}\right)$.

Now we give the following lemma which is needed in the next theorem.

Lemma $2.8[31] A \in\left(\ell_{\infty}: c_{0}\right) \Leftrightarrow \lim _{n \rightarrow \infty} \sum_{k}\left|a_{n k}\right|=0$.

Theorem 2.9 Let a sequence $z=\left(z_{k}\right)$ be as follows:

$$
z_{k}=\left|\frac{1}{\lambda_{k}-\lambda_{k-1}} \sum_{\vartheta=0}^{m-1}\left(\begin{array}{c}
m-1 \\
\vartheta
\end{array}\right) r^{m-\vartheta-1} s^{\vartheta}\left(\lambda_{k+\vartheta}-\lambda_{k+\vartheta-1}\right)\right|
$$

for all $k \in \mathbb{N}$. Then the inclusion $\ell_{\infty} \subset c_{0}^{\lambda}\left(G^{m}\right)$ is strict if and only if $z \in c_{0}^{\lambda}$.

Proof We assume that the inclusion $\ell_{\infty} \subset c_{0}^{\lambda}\left(G^{m}\right)$ holds. Then it is obvious that for every $x \in \ell_{\infty}, x \in c_{0}^{\lambda}\left(G^{m}\right)$, namely $T^{m \lambda} \in c_{0}$. Thus $T^{m \lambda} \in\left(\ell_{\infty}: c_{0}\right)$. If we consider the last result and Lemma 2.8, we deduce that

$$
\lim _{n \rightarrow \infty} \sum_{k}\left|t_{n k}^{m \lambda}\right|=0
$$


Also, by using the definition of the matrix $T^{m \lambda}=\left(t_{n k}^{m \lambda}\right)$, we obtain by the equality above that

$$
\begin{aligned}
& \lim _{n \rightarrow \infty} \frac{1}{\lambda_{n}} \sum_{k=0}^{n-m+1}\left|\sum_{\vartheta=0}^{m-1}\left(\begin{array}{c}
m-1 \\
\vartheta
\end{array}\right) r^{m-\vartheta-1} s^{\vartheta}\left(\lambda_{k+\vartheta}-\lambda_{k+\vartheta-1}\right)\right|=0, \\
& \lim _{n \rightarrow \infty}\left|\frac{1}{\lambda_{n}} \sum_{\vartheta=1}^{m-1}\left(\begin{array}{c}
m-1 \\
\vartheta-1
\end{array}\right) r^{m-\vartheta} s^{\vartheta-1}\left(\lambda_{n-m+\vartheta+1}-\lambda_{n-m+\vartheta}\right)\right|=0, \\
& \vdots \\
& \lim _{n \rightarrow \infty}\left|\frac{r^{m-1}\left(\lambda_{n-1}-\lambda_{n-2}\right)+(m-1) r^{m-2} s\left(\lambda_{n}-\lambda_{n-1}\right)}{\lambda_{n}}\right|=0, \\
& \lim _{n \rightarrow \infty}\left|r^{m-1}\right| \frac{\lambda_{n}-\lambda_{n-1}}{\lambda_{n}}=0 .
\end{aligned}
$$

By considering equalities $(2.5),(2.6), \ldots,(2.3+\mathrm{m})$ and $(2.4+\mathrm{m})$, we conclude that

$$
\lim _{n \rightarrow \infty} \frac{\lambda_{n-1}}{\lambda_{n}}=1, \quad \lim _{n \rightarrow \infty} \frac{\lambda_{n-2}}{\lambda_{n}}=1, \quad \ldots, \quad \lim _{n \rightarrow \infty} \frac{\lambda_{n-m+1}}{\lambda_{n}}=1 .
$$

For all $n \geq m-1$, we write the equality as follows:

$$
\begin{gathered}
\frac{1}{\lambda_{n}} \sum_{k=0}^{n-m+1}\left|\sum_{\vartheta=0}^{m-1}\left(\begin{array}{c}
m-1 \\
\vartheta
\end{array}\right) r^{m-\vartheta-1} s^{\vartheta}\left(\lambda_{k+\vartheta}-\lambda_{k+\vartheta-1}\right)\right| \\
\quad=\frac{\lambda_{n-m+1}}{\lambda_{n}}\left[\frac{1}{\lambda_{n-m+1}} \sum_{k=0}^{n-m+1}\left(\lambda_{k}-\lambda_{k-1}\right) z_{k}\right] .
\end{gathered}
$$

By combining $\lim _{n \rightarrow \infty} \frac{\lambda_{n-m+1}}{\lambda_{n}}=1,(2.5)$ and $(2.5+\mathrm{m})$, we deduce that

$$
\lim _{n \rightarrow \infty} \frac{1}{\lambda_{n-m+1}} \sum_{k=0}^{n-m+1}\left(\lambda_{k}-\lambda_{k-1}\right) z_{k}=0
$$

This means that $z \in c_{0}^{\lambda}$.

On the contrary, assume that $z \in c_{0}^{\lambda}$. Then we have $(2.6+\mathrm{m})$. Also, for all $n \geq m-1$, we write the inequality as follows:

$$
\begin{aligned}
0 & \leq\left|\frac{r^{m-1} \lambda_{n-m+1}+(m-1) r^{m-2} s\left(\lambda_{n-m+2}-\lambda_{0}\right)+\cdots+s^{m-1}\left(\lambda_{n}-\lambda_{m-2}\right)}{\lambda_{n}}\right| \\
& =\left|\frac{1}{\lambda_{n}} \sum_{k=0}^{n-m+1} \sum_{\vartheta=0}^{m-1}\left(\begin{array}{c}
m-1 \\
\vartheta
\end{array}\right) r^{m-\vartheta-1} s^{\vartheta}\left(\lambda_{k+\vartheta}-\lambda_{k+\vartheta-1}\right)\right| \\
& \leq \frac{1}{\lambda_{n}} \sum_{k=0}^{n-m+1}\left|\sum_{\vartheta=0}^{m-1}\left(\begin{array}{c}
m-1 \\
\vartheta
\end{array}\right) r^{m-\vartheta-1} s^{\vartheta}\left(\lambda_{k+\vartheta}-\lambda_{k+\vartheta-1}\right)\right| \\
& =\frac{1}{\lambda_{n}} \sum_{k=0}^{n-m+1}\left(\lambda_{k}-\lambda_{k-1}\right) z_{k} \\
& \leq \frac{1}{\lambda_{n-m+1}} \sum_{k=0}^{n-m+1}\left(\lambda_{k}-\lambda_{k-1}\right) z_{k} .
\end{aligned}
$$


By combining the last inequality and $(2.6+\mathrm{m})$, we conclude that

$$
\lim _{n \rightarrow \infty} \frac{r^{m-1} \lambda_{n-m+1}+(m-1) r^{m-2} s\left(\lambda_{n-m+2}-\lambda_{0}\right)+\cdots+s^{m-1}\left(\lambda_{n}-\lambda_{m-2}\right)}{\lambda_{n}}=0 .
$$

Specially, if we take $(r=1, s=-1$ and $m=2),(r=1, s=-1$ and $m=3), \ldots$ then we obtain $\lim _{n \rightarrow \infty} \frac{\lambda_{n}-\lambda_{n-1}}{\lambda_{n}}=0, \lim _{n \rightarrow \infty} \frac{\lambda_{n-1}-\lambda_{n-2}}{\lambda_{n}}=0, \ldots$, respectively. These equalities show that $(2.4+\mathrm{m}),(2.3+\mathrm{m}), \ldots,(2.6)$ and $(2.5)$ hold, respectively. If we take into account the last result and Lemma 2.8, we conclude that $T^{m \lambda} \in\left(\ell_{\infty}: c_{0}\right)$. Thus, the inclusion $\ell_{\infty} \subset c_{0}^{\lambda}\left(G^{m}\right)$ holds and is strict by Corollary 2.7. This step completes the proof.

\section{The Schauder basis and $\alpha$-, $\beta$ - and $\boldsymbol{\gamma}$-duals}

In the present section, we give the Schauder basis and determine $\alpha-, \beta$ - and $\gamma$-duals of the sequence spaces $c_{0}^{\lambda}\left(G^{m}\right)$ and $c^{\lambda}\left(G^{m}\right)$.

Let $\left(X,\|x\|_{X}\right)$ be a normed space. A set $\left\{x_{k}: x_{k} \in X, k \in \mathbb{N}\right\}$ is called a Schauder basis for $X$ if for every $x \in X$ there exist unique scalars $\mu_{k}, k \in \mathbb{N}$, such that $x=\sum_{k} \mu_{k} x_{k} ;$ i.e.,

$$
\left\|x-\sum_{k=0}^{n} \mu_{k} x_{k}\right\|_{X} \longrightarrow 0
$$

as $n \rightarrow \infty$.

Note that the Hamel basis is free from topology, whereas the Schauder basis involves convergence and hence topology (see [1]).

For example, let $e^{(k)}$ be a sequence with 1 in the $k$ th place and zeros elsewhere, and let $e=(1,1,1, \ldots)$. Then the sequence $\left(e^{(k)}\right)$ is a Schauder basis for $c_{0}$. Moreover, $\left\{e, e^{0}, e^{1}, \ldots\right\}$ is a Schauder basis for $c$.

Due to the transformation, $L$ defined in the proof of Theorem 2.2 is an isomorphism; the inverse image of $\left(e^{(k)}\right)$ is a Schauder basis for $c_{0}^{\lambda}\left(G^{m}\right)$.

Now we give the following results.

Theorem 3.1 Let $\sigma_{k}=\left\{T^{m \lambda} x\right\}_{k}$ for all $k \in \mathbb{N}$. For every fixed $k \in \mathbb{N}$, we define the sequences $h=\left(h_{n}\right)$ and $h_{(k)}^{m \lambda}(r, s)=\left\{h_{n(k)}^{m \lambda}(r, s)\right\}_{n \in \mathbb{N}}$ such that

$$
\begin{aligned}
& h_{n}=\frac{1}{r^{m-1}} \sum_{k=0}^{n}\left(\begin{array}{c}
m+k-2 \\
m-2
\end{array}\right)\left(-\frac{s}{r}\right)^{k}, \\
& h_{n(k)}^{m \lambda}(r, s)= \begin{cases}\frac{1}{r^{m-2}}\left(-\frac{s}{r}\right)^{n-k}\left[\frac{\left(\begin{array}{c}
m+n-k-2 \\
m-2
\end{array}\right) \lambda_{k}}{r\left(\lambda_{k}-\lambda_{k-1}\right)}+\frac{\left(\begin{array}{c}
m+n-k-3 \\
m-2
\end{array}\right) \lambda_{k}}{s\left(\lambda_{k+1}-\lambda_{k}\right)}\right], & k<n, \\
\frac{\lambda_{k}}{r^{m-1}\left(\lambda_{k}-\lambda_{k-1}\right)}, & k=n, \\
0, & k>n .\end{cases}
\end{aligned}
$$

Then

(a) The sequence $\left\{h_{(k)}^{m \lambda}(r, s)\right\}_{k \in \mathbb{N}}$ is a Schauder basis for the space $c_{0}^{\lambda}\left(G^{m}\right)$, and every $x \in c_{0}^{\lambda}\left(G^{m}\right)$ has a unique representation of the form

$$
x=\sum_{k} \sigma_{k} h_{(k)}^{m \lambda}(r, s)
$$


(b) The sequence $\left\{h, h_{(0)}^{m \lambda}(r, s), h_{(1)}^{m \lambda}(r, s), \ldots\right\}$ is a Schauder basis for the space $c^{\lambda}\left(G^{m}\right)$, and every $x \in c^{\lambda}\left(G^{m}\right)$ has a unique representation of the form

$$
x=l h+\sum_{k}\left[\sigma_{k}-l\right] h_{(k)}^{m \lambda}(r, s)
$$

where $l=\lim _{k \rightarrow \infty} \sigma_{k}$.

If we consider the results of Theorem 2.1 and Theorem 3.1, we give the following result.

Corollary 3.2 The sequence spaces $c_{0}^{\lambda}\left(G^{m}\right)$ and $c^{\lambda}\left(G^{m}\right)$ are separable.

Given arbitrary sequence spaces $X$ and $Y$, the set $M(X, Y)$ defined by

$$
M(X, Y)=\left\{y=\left(y_{k}\right) \in w: x y=\left(x_{k} y_{k}\right) \in Y \text { for all } x=\left(x_{k}\right) \in X\right\}
$$

is called the multiplier space of $X$ and $Y$. For a sequence space $Z$ with $Y \subset Z \subset X$, one can easily observe that $M(X, Y) \subset M(Z, Y)$ and $M(X, Y) \subset M(X, Z)$ hold, in turn.

By using the sequence spaces $\ell_{1}, c s$ and $b s$ and notation (3.1), the $\alpha-, \beta$ - and $\gamma$-duals of a sequence space $X$ are defined by

$$
X^{\alpha}=M\left(X, \ell_{1}\right), \quad X^{\beta}=M(X, c s) \quad \text { and } \quad X^{\gamma}=M(X, b s),
$$

respectively.

Now we give some properties which are needed in the next lemma

$$
\begin{aligned}
& \sup _{K \in \mathcal{F}} \sum_{n}\left|\sum_{k \in K} a_{n k}\right|^{p}<\infty, \\
& \sup _{n \in \mathbb{N}} \sum_{k}\left|a_{n k}\right|<\infty, \\
& \lim _{n \rightarrow \infty} a_{n k}=\alpha_{k} \quad \text { for each } k \in \mathbb{N}, \\
& \lim _{n \rightarrow \infty} \sum_{k} a_{n k}=\alpha,
\end{aligned}
$$

where $\mathcal{F}$ is the collection of all finite subsets of $\mathbb{N}$ and $p \in[1, \infty)$.

Lemma 3.3 [31] Let $A=\left(a_{n k}\right)$ be an infinite matrix, then the following hold:

(i) $A=\left(a_{n k}\right) \in\left(c_{0}: \ell_{1}\right)=\left(c: \ell_{1}\right) \Leftrightarrow(3.2)$ holds with $p=1$;

(ii) $A=\left(a_{n k}\right) \in\left(c_{0}: c\right) \Leftrightarrow$ (3.3) and (3.4) hold;

(iii) $A=\left(a_{n k}\right) \in(c: c) \Leftrightarrow$ (3.3), (3.4) and (3.5) hold;

(iv) $A=\left(a_{n k}\right) \in\left(c_{0}: \ell_{\infty}\right)=\left(c: \ell_{\infty}\right) \Leftrightarrow(3.3)$ holds;

(v) $A=\left(a_{n k}\right) \in\left(c_{0}: \ell_{p}\right)=\left(c: \ell_{p}\right) \Leftrightarrow(3.2)$ holds with $1 \leq p<\infty$;

(vi) $A=\left(a_{n k}\right) \in\left(c: c_{0}\right) \Leftrightarrow$ (3.3), (3.4) and (3.5) hold with $\alpha_{k}=0, \forall k \in \mathbb{N}$ and $\alpha=0$;

(vii) $A=\left(a_{n k}\right) \in\left(c_{0}: c_{0}\right) \Leftrightarrow(3.3)$ and (3.4) hold with $\alpha_{k}=0, \forall k \in \mathbb{N}$. 
Theorem 3.4 Define the set $u_{1}^{m \lambda}(r, s)$ by

$$
u_{1}^{m \lambda}(r, s)=\left\{a=\left(a_{n}\right) \in w: \sup _{K \in \mathcal{F}} \sum_{n}\left|\sum_{k \in K} d_{n k}^{m \lambda}\right|<\infty\right\},
$$

where the matrix $D^{m \lambda}=\left(d_{n k}^{m \lambda}\right)$ is defined by means of the sequence $a=\left(a_{n}\right)$ by

$$
d_{n k}^{m \lambda}(r, s)= \begin{cases}\frac{1}{r^{m-2}}\left(-\frac{s}{r}\right)^{n-k}\left[\frac{\left(\frac{m+n-k-2}{m-2}\right) \lambda_{k}}{r\left(\lambda_{k}-\lambda_{k-1}\right)}+\frac{\left(\begin{array}{cc}
m+n-k-3 \\
m-2
\end{array}\right) \lambda_{k}}{s\left(\lambda_{k+1}-\lambda_{k}\right)}\right] a_{n}, & k<n, \\
\frac{\lambda_{n}}{r^{m-1}\left(\lambda_{n}-\lambda_{n-1}\right)} a_{n}, & k=n, \\
0, & k>n .\end{cases}
$$

Then $\left\{c_{0}^{\lambda}\left(G^{m}\right)\right\}^{\alpha}=\left\{c^{\lambda}\left(G^{m}\right)\right\}^{\alpha}=u_{1}^{m \lambda}(r, s)$.

Proof For given $a=\left(a_{n}\right) \in w$, by taking into account the sequence $x=\left(x_{n}\right)$ that is defined in the proof of Theorem 2.2, we obtain

$$
a_{n} x_{n}=\frac{1}{r^{m-1}} \sum_{k=0}^{n}\left(\begin{array}{c}
m+n-k-2 \\
m-2
\end{array}\right)\left(-\frac{s}{r}\right)^{n-k} \sum_{i=k-1}^{k}(-1)^{k-i} \frac{\lambda_{i}}{\lambda_{k}-\lambda_{k-1}} a_{n} y_{i}=D_{n}^{m \lambda}(y)
$$

for all $n \in \mathbb{N}$. If we consider the equality above, we conclude that $a x=\left(a_{n} x_{n}\right) \in \ell_{1}$ whenever $x=\left(x_{k}\right) \in c_{0}^{\lambda}\left(G^{m}\right)$ or $c^{\lambda}\left(G^{m}\right)$ if and only if $D^{m \lambda} y \in \ell_{1}$ whenever $y=\left(y_{k}\right) \in c_{0}$ or $c$. This means that $a=\left(a_{n}\right) \in\left\{c_{0}^{\lambda}\left(G^{m}\right)\right\}^{\alpha}=\left\{c^{\lambda}\left(G^{m}\right)\right\}^{\alpha}$ if and only if $D^{m \lambda} \in\left(c_{0}: \ell_{1}\right)=\left(c: \ell_{1}\right)$. If we consider this and Lemma 3.3(i), we write

$$
a=\left(a_{n}\right) \in\left\{c_{0}^{\lambda}\left(G^{m}\right)\right\}^{\alpha}=\left\{c^{\lambda}\left(G^{m}\right)\right\}^{\alpha} \Leftrightarrow \sup _{K \in \mathcal{F}} \sum_{n}\left|\sum_{k \in K} d_{n k}^{m \lambda}\right|<\infty
$$

and conclude $\left\{c_{0}^{\lambda}\left(G^{m}\right)\right\}^{\alpha}=\left\{c^{\lambda}\left(G^{m}\right)\right\}^{\alpha}=u_{1}^{m \lambda}(r, s)$. This step completes the proof.

Theorem 3.5 Given the sets $u_{2}^{m \lambda}(r, s), u_{3}^{m \lambda}(r, s), u_{4}^{m \lambda}(r, s)$ and $u_{5}^{m \lambda}(r, s)$ as follows:

$$
\begin{aligned}
& u_{2}^{m \lambda}(r, s)=\left\{a=\left(a_{k}\right) \in w: \sum_{j=k}^{\infty}\left(\begin{array}{c}
m+n-j-2 \\
m-2
\end{array}\right)\left(-\frac{s}{r}\right)^{n-j} a_{j} \text { exists for all } k \in \mathbb{N}\right\}, \\
& u_{3}^{m \lambda}(r, s)=\left\{a=\left(a_{k}\right) \in w: \sup _{n \in \mathbb{N}} \sum_{k=0}^{n-1}\left|b_{k}^{m \lambda}(n)\right|<\infty\right\}, \\
& u_{4}^{m \lambda}(r, s)=\left\{a=\left(a_{k}\right) \in w: \sup _{n \in \mathbb{N}}\left|\frac{\lambda_{n}}{r^{m-1}\left(\lambda_{n}-\lambda_{n-1}\right)} a_{n}\right|<\infty\right\}
\end{aligned}
$$

and

$$
u_{5}^{m \lambda}(r, s)=\left\{a=\left(a_{k}\right) \in w: \sum_{k} \frac{1}{r^{m-1}} \sum_{j=0}^{k}\left(\begin{array}{c}
m+j-2 \\
m-2
\end{array}\right)\left(-\frac{s}{r}\right)^{j} a_{k} \text { converges }\right\},
$$


where

$$
\begin{aligned}
b_{k}^{m \lambda}(n)= & \lambda_{k}\left[\frac{a_{k}}{r^{m-1}\left(\lambda_{k}-\lambda_{k-1}\right)}\right. \\
& \left.+\frac{1}{r^{m-2}} \sum_{j=k+1}^{n}\left(-\frac{s}{r}\right)^{n-j}\left(\frac{\left(\begin{array}{c}
m+n-j-2 \\
m-2
\end{array}\right)}{r\left(\lambda_{k}-\lambda_{k-1}\right)}+\frac{\left(\begin{array}{c}
m+n-j-3 \\
m-2
\end{array}\right)}{s\left(\lambda_{k+1}-\lambda_{k}\right)}\right) a_{j}\right], \quad k<n .
\end{aligned}
$$

Then $\left\{c_{0}^{\lambda}\left(G^{m}\right)\right\}^{\beta}=u_{2}^{m \lambda}(r, s) \cap u_{3}^{m \lambda}(r, s) \cap u_{4}^{m \lambda}(r, s)$ and $\left\{c^{\lambda}\left(G^{m}\right)\right\}^{\beta}=u_{3}^{m \lambda}(r, s) \cap u_{4}^{m \lambda}(r, s) \cap$ $u_{5}^{m \lambda}(r, s)$.

Proof Given $a=\left(a_{k}\right) \in w$, by considering the sequence $x=\left(x_{k}\right)$ that is defined in the proof of Theorem 2.2, we obtain

$$
\begin{aligned}
\sum_{k=0}^{n} a_{k} x_{k}= & \sum_{k=0}^{n}\left\{\frac{1}{r^{m-1}} \sum_{j=0}^{k}\left(\begin{array}{c}
m+k-j-2 \\
m-2
\end{array}\right)\left(-\frac{s}{r}\right)^{k-j} \sum_{i=j-1}^{j}(-1)^{j-i} \frac{\lambda_{i}}{\lambda_{j}-\lambda_{j-1}} y_{i}\right\} a_{k} \\
= & \sum_{k=0}^{n-1} \lambda_{k}\left[\frac{a_{k}}{r^{m-1}\left(\lambda_{k}-\lambda_{k-1}\right)}\right. \\
& \left.+\frac{1}{r^{m-2}} \sum_{j=k+1}^{n}\left(-\frac{s}{r}\right)^{n-j}\left(\frac{\left(\begin{array}{c}
m+n-j-2 \\
m-2
\end{array}\right)}{r\left(\lambda_{k}-\lambda_{k-1}\right)}+\frac{\left(\begin{array}{c}
m+n-j-3 \\
m-2
\end{array}\right)}{s\left(\lambda_{k+1}-\lambda_{k}\right)}\right) a_{j}\right] y_{k} \\
& +\frac{\lambda_{n}}{r^{m-1}\left(\lambda_{n}-\lambda_{n-1}\right)} a_{n} y_{n} \\
= & \sum_{k=0}^{n-1} b_{k}^{m \lambda}(n) y_{k}+\frac{\lambda_{n}}{r^{m-1}\left(\lambda_{n}-\lambda_{n-1}\right)} a_{n} y_{n} \\
= & V_{n}^{m \lambda}(y)
\end{aligned}
$$

$\forall n \in \mathbb{N}$, where the matrix $V^{m \lambda}=\left(v_{n k}^{m \lambda}\right)$ is defined as follows:

$$
v_{n k}^{m \lambda}(r, s)= \begin{cases}b_{k}^{m \lambda}(n), & k<n, \\ \frac{\lambda_{n}}{r^{m-1}\left(\lambda_{n}-\lambda_{n-1}\right)} a_{n}, & k=n, \\ 0, & k>n\end{cases}
$$

for all $n, k \in \mathbb{N}$. Then $a x=\left(a_{k} x_{k}\right) \in c s$ whenever $x=\left(x_{k}\right) \in c_{0}^{\lambda}\left(G^{m}\right)$ if and only if $V^{m \lambda} y \in c$ whenever $y=\left(y_{k}\right) \in c_{0}$. This shows that $a=\left(a_{k}\right) \in\left\{c_{0}^{\lambda}\left(G^{m}\right)\right\}^{\beta}$ if and only if $V^{m \lambda} \in\left(c_{0}: c\right)$. If we consider this and Lemma 3.3(ii), we obtain

$$
\begin{aligned}
& \sum_{j=k}^{\infty}\left(\begin{array}{c}
m+n-j-2 \\
m-2
\end{array}\right)\left(-\frac{s}{r}\right)^{n-j} a_{j} \text { exists } \quad \forall k \in \mathbb{N}, \\
& \sup _{n \in \mathbb{N}} \sum_{k=0}^{n-1}\left|b_{k}^{m \lambda}(n)\right|<\infty
\end{aligned}
$$


and

$$
\sup _{n \in \mathbb{N}}\left|\frac{\lambda_{n}}{r^{m-1}\left(\lambda_{n}-\lambda_{n-1}\right)} a_{n}\right|<\infty .
$$

These results show that $\left\{c_{0}^{\lambda}\left(G^{m}\right)\right\}^{\beta}=u_{2}^{m \lambda}(r, s) \cap u_{3}^{m \lambda}(r, s) \cap u_{4}^{m \lambda}(r, s)$.

By using a similar way, we obtain $a=\left(a_{k}\right) \in\left\{c^{\lambda}\left(G^{m}\right)\right\}^{\beta}$ if and only if $V^{m \lambda} \in(c: c)$. If we consider this and Lemma 3.3(iii), we conclude that (3.6), (3.7) and (3.8) hold.

Moreover, one can easily see that

$$
\frac{1}{r^{m-1}} \sum_{k=0}^{n} \sum_{j=0}^{k}\left(\begin{array}{c}
m+j-2 \\
m-2
\end{array}\right)\left(-\frac{s}{r}\right)^{j} a_{k}=\sum_{k=0}^{n-1} b_{k}^{m \lambda}(n)+\frac{\lambda_{n}}{r^{m-1}\left(\lambda_{n}-\lambda_{n-1}\right)} a_{n}=\sum_{k} v_{n k}^{m \lambda} .
$$

As a consequence, we derive from (3.5) that

$$
\left\{\frac{1}{r^{m-1}} \sum_{j=0}^{k}\left(\begin{array}{c}
m+j-2 \\
m-2
\end{array}\right)\left(-\frac{s}{r}\right)^{j} a_{k}\right\} \in c s .
$$

Since condition (3.6) is weaker, it can be omitted.

Therefore we conclude that $\left\{c^{\lambda}\left(G^{m}\right)\right\}^{\beta}=u_{3}^{m \lambda}(r, s) \cap u_{4}^{m \lambda}(r, s) \cap u_{5}^{m \lambda}(r, s)$. This step completes the proof.

Theorem $3.6\left\{c_{0}^{\lambda}\left(G^{m}\right)\right\}^{\gamma}=\left\{c^{\lambda}\left(G^{m}\right)\right\}^{\gamma}=u_{3}^{m \lambda}(r, s) \cap u_{4}^{m \lambda}(r, s)$.

Proof It can be proved by combining the proof method of Theorem 3.5 and Lemma 3.3(iv).

\section{Matrix transformations}

In the present section, we determine some matrix classes related to the sequence spaces $c_{0}^{\lambda}\left(G^{m}\right)$ and $c^{\lambda}\left(G^{m}\right)$. Let us begin with two lemmas which are needed in the proof of theorems.

Lemma 4.1 [3] Any matrix map between BK-spaces is continuous.

Lemma 4.2 [32] Let $X, Y$ be any two sequence spaces, $A$ be an infinite matrix and $U$ be a triangle matrix. Then $A \in\left(X: Y_{U}\right) \Leftrightarrow U A \in(X: Y)$.

For simplicity of notation, in what follows, we use the following equalities.

$$
\begin{aligned}
b_{n k}^{m \lambda}(i)= & \lambda_{k}\left[\frac{a_{n k}}{r^{m-1}\left(\lambda_{k}-\lambda_{k-1}\right)}\right. \\
& \left.+\frac{1}{r^{m-2}} \sum_{j=k+1}^{i}\left(-\frac{s}{r}\right)^{n-j}\left(\frac{\left(\begin{array}{c}
m+n-j-2 \\
m-2
\end{array}\right)}{r\left(\lambda_{k}-\lambda_{k-1}\right)}+\frac{\left(\begin{array}{c}
m+n-j-3 \\
m-2
\end{array}\right)}{s\left(\lambda_{k+1}-\lambda_{k}\right)}\right) a_{n j}\right], \quad k<i
\end{aligned}
$$

and

$$
b_{n k}^{m \lambda}=\lambda_{k}\left[\frac{a_{n k}}{r^{m-1}\left(\lambda_{k}-\lambda_{k-1}\right)}+\frac{1}{r^{m-2}} \sum_{j=k+1}^{\infty}\left(-\frac{s}{r}\right)^{n-j}\left(\frac{\left(\begin{array}{c}
m+n-j-2 \\
m-2
\end{array}\right)}{r\left(\lambda_{k}-\lambda_{k-1}\right)}+\frac{\left(\begin{array}{c}
m+n-j-3 \\
m-2
\end{array}\right)}{s\left(\lambda_{k+1}-\lambda_{k}\right)}\right) a_{n j}\right]
$$


for all $n, k, i \in \mathbb{N}$ provided the convergence of the series. Also, unless stated otherwise, we assume throughout Section 4 that the sequence $y=\left(y_{k}\right)$ is connected with the sequence $x=\left(x_{k}\right)$ as follows:

$$
x_{k}=\frac{1}{r^{m-1}} \sum_{j=0}^{k}\left(\begin{array}{c}
m+k-j-2 \\
m-2
\end{array}\right)\left(-\frac{s}{r}\right)^{k-j} \sum_{\varphi=j-1}^{j}(-1)^{j-\varphi} \frac{\lambda_{\varphi}}{\lambda_{j}-\lambda_{j-1}} y_{\varphi}
$$

for all $k \in \mathbb{N}$.

Theorem 4.3 Given an infinite matrix $A=\left(a_{n k}\right)$ of complex numbers, the following statements hold.

(1) Let $1 \leq p<\infty$. Then $A \in\left(c^{\lambda}\left(G^{m}\right): \ell_{p}\right)$ if and only if

$$
\begin{aligned}
& \sup _{K \in \mathcal{F}} \sum_{n}\left|\sum_{k \in K} b_{n k}^{m \lambda}\right|^{p}<\infty, \\
& \sup _{i \in \mathbb{N}} \sum_{k=0}^{i-1}\left|b_{n k}^{m \lambda}(i)\right|<\infty \quad(n \in \mathbb{N}), \\
& \left\{\frac{1}{r^{m-1}} \sum_{j=0}^{k}\left(\begin{array}{c}
m+j-2 \\
m-2
\end{array}\right)\left(-\frac{s}{r}\right)^{j} a_{n k}\right\}_{k=0}^{\infty} \in c s \quad(n \in \mathbb{N}), \\
& \lim _{k \rightarrow \infty} \frac{\lambda_{k}}{r^{m-1}\left(\lambda_{k}-\lambda_{k-1}\right)} a_{n k}=a_{n} \quad(n \in \mathbb{N}), \\
& \left(a_{n}\right) \in \ell_{p} .
\end{aligned}
$$

(2) $A \in\left(c^{\lambda}\left(G^{m}\right): \ell_{\infty}\right)$ if and only if (4.3) and (4.4) hold, and

$$
\begin{aligned}
& \sup _{n \in \mathbb{N}} \sum_{k}\left|b_{n k}^{m \lambda}\right|<\infty, \\
& \left(a_{n}\right) \in \ell_{\infty} .
\end{aligned}
$$

Proof For a given sequence $x=\left(x_{k}\right) \in c^{\lambda}\left(G^{m}\right)$, we assume that conditions (4.1)-(4.5) hold. Then, by remembering Theorem 3.5, we deduce that $\left\{a_{n k}\right\}_{k \in \mathbb{N}} \in\left\{c^{\lambda}\left(G^{m}\right)\right\}^{\beta}$ for all $n \in \mathbb{N}$. Therefore the $A$-transform of $x$ exists. Moreover, it is trivial that $y \in c$, namely $\exists l \in \mathbb{C} \ni$ $\lim _{k \rightarrow \infty}\left|y_{k}-l\right|=0$. Furthermore, if we consider Lemmas 3.3 and 4.1, we conclude that the matrix $B^{m \lambda} \in\left(c: \ell_{p}\right)$, where $1 \leq p<\infty$.

Now, we consider the following equality:

$$
\sum_{k=0}^{i} a_{n k} x_{k}=\sum_{k=0}^{i-1} b_{n k}^{m \lambda}(i) y_{k}+\frac{\lambda_{i}}{r^{m-1}\left(\lambda_{i}-\lambda_{i-1}\right)} a_{n i} y_{i} \quad(n, i \in \mathbb{N}) .
$$

Then $B^{m \lambda} y$ exists and the series $\sum_{k} b_{n k}^{m \lambda} y_{k}$ converges for all $n \in \mathbb{N}$. Moreover, we derive from (4.3) that the series $\sum_{j=k}^{\infty}\left(-\frac{s}{r}\right)^{n-j}\left[\frac{\left(\frac{m+n-2-2}{m-2}\right)}{r\left(\lambda_{k}-\lambda_{k-1}\right)}+\frac{\left(\begin{array}{l}m+n-j-3 \\ m-2\end{array}\right)}{s\left(\lambda_{k+1}-\lambda_{k}\right)}\right] a_{n j}$ converges for all $n, k \in \mathbb{N}$; and therefore $\lim _{i \rightarrow \infty} b_{n k}^{m \lambda}(i)=b_{n k}^{m \lambda}$. Hence, if we take limit (4.8) side by side as $i \rightarrow \infty$, we 
obtain by (4.4) that

$$
\sum_{k} a_{n k} x_{k}=\sum_{k} b_{n k}^{m \lambda} y_{k}+l a_{n}
$$

for all $n \in \mathbb{N}$. Then we write the equality above as follows:

$$
A_{n}(x)=B_{n}^{m \lambda}(y)+l a_{n}
$$

for all $n \in \mathbb{N}$. Also, we know $\left(B^{m \lambda} y\right)_{n} \in \ell_{p}$ and $a=\left(a_{n}\right) \in \ell_{p}$. Then we have $\left\|B^{m \lambda} y\right\|_{\ell_{p}}<\infty$ and $\left\|a_{n}\right\|_{\ell_{p}}<\infty$. By taking $\ell_{p}$-norm (4.10) side by side, we obtain that

$$
\|A x\|_{\ell_{p}} \leq\left\|B^{m \lambda} y\right\|_{\ell_{p}}+|l|\left\|a_{n}\right\|_{\ell_{p}}<\infty .
$$

Therefore $A x \in \ell_{p}$ and so $A \in\left(c^{\lambda}\left(G^{m}\right): \ell_{p}\right)$.

On the contrary, assume that $A \in\left(c^{\lambda}\left(G^{m}\right): \ell_{p}\right)$, where $1 \leq p<\infty$. This leads us to $\left\{a_{n k}\right\}_{k \in \mathbb{N}} \in\left\{c^{\lambda}\left(G^{m}\right)\right\}^{\beta}$ for all $n \in \mathbb{N}$. Then, if we consider Theorem 3.5, conditions (4.2) and (4.3) hold.

We know that $c^{\lambda}\left(G^{m}\right)$ and $\ell_{p}$ are $B K$-spaces. If we combine this fact and Lemma 4.1, we conclude that there is a constant $M>0$ such that

$$
\|A x\|_{\ell_{p}} \leq M\|x\|_{c^{\lambda}\left(G^{m}\right)}
$$

holds for all $x \in c^{\lambda}\left(G^{m}\right)$. Let us define a sequence $z=\left(z_{k}\right)$ such that $z=\sum_{k \in K} h_{(k)}^{m \lambda}(r, s)$ for every fixed $k \in \mathbb{N}$, where the sequence $h_{(k)}^{m \lambda}(r, s)=\left\{h_{n(k)}^{m \lambda}(r, s)\right\}_{n \in \mathbb{N}}$ and $K \in \mathcal{F}$.

We know from Theorem 3.1 that $z \in c^{\lambda}\left(G^{m}\right)$ and $T^{m \lambda}\left(h_{(k)}^{m \lambda}(r, s)\right)=e^{(k)}, \forall k \in \mathbb{N}$. Then we obtain

$$
\|z\|_{c^{\lambda}\left(G^{m}\right)}=\left\|T^{m \lambda}(z)\right\|_{\ell_{\infty}}=\left\|\sum_{k \in K} T^{m \lambda}\left(h_{(k)}^{m \lambda}(r, s)\right)\right\|_{\ell_{\infty}}=\left\|\sum_{k \in K} e^{(k)}\right\|_{\ell_{\infty}}=1
$$

and

$$
A_{n}(z)=\sum_{k \in K} A_{n}\left(h_{(k)}^{m \lambda}(r, s)\right)=\sum_{k \in K} \sum_{j} a_{n j} h_{j(k)}^{m \lambda}(r, s)=\sum_{k \in K} b_{n k}^{m \lambda}
$$

for all $n \in \mathbb{N}$. Since inequality (4.11) holds for every $x \in c^{\lambda}\left(G^{m}\right)$, the inequality is satisfied also for $z \in c^{\lambda}\left(G^{m}\right)$. Then we have

$$
\left(\sum_{n}\left|\sum_{k \in K} b_{n k}^{m \lambda}\right|^{p}\right)^{\frac{1}{p}} \leq M
$$

for all $K \in \mathcal{F}$. Therefore (4.1) holds. If we consider this and Lemma 3.3(v), we conclude that $B^{m \lambda}=\left(b_{n k}^{m \lambda}\right) \in\left(c: \ell_{p}\right)$. Given $y=\left(y_{k}\right) \in c \backslash c_{0}$. Then $x \in c^{\lambda}\left(G^{m}\right)$ so that $y=T^{m \lambda}(x)$. 
Hence $A x$ and $B^{m \lambda} y$ exist. So one can easily see that the series $\sum_{k} a_{n k} x_{k}$ and $\sum_{k} b_{n k}^{m \lambda} y_{k}$ are convergent for all $n \in \mathbb{N}$. Thus, we conclude that

$$
\lim _{i \rightarrow \infty} \sum_{k=0}^{i-1} b_{n k}^{m \lambda}(i) y_{k}=\sum_{k} b_{n k}^{m \lambda} y_{k}
$$

or all $n \in \mathbb{N}$. As a consequence, if we pass to the limit in (4.8) as $i \rightarrow \infty$, we obtain

$$
\lim _{i \rightarrow \infty} \frac{\lambda_{i}}{r^{m-1}\left(\lambda_{i}-\lambda_{i-1}\right)} a_{n i} y_{i} \text { exists }
$$

for all $n \in \mathbb{N}$. Because of $y=\left(y_{k}\right) \in c \backslash c_{0}$, this leads us

$$
\lim _{i \rightarrow \infty} \frac{\lambda_{i}}{r^{m-1}\left(\lambda_{i}-\lambda_{i-1}\right)} a_{n i} \text { exists }
$$

for all $n \in \mathbb{N}$. Therefore, (4.4) holds. If we take $l=\lim _{k \rightarrow \infty} y_{k}$, also relation (4.10) holds. Because of $A x, B^{m \lambda} y \in \ell_{p}$, we conclude $a=\left(a_{n}\right) \in \ell_{p}$. The last result is the necessity of (4.5). This step completes the proof of part (1).

If we take Lemma 3.3(iv) instead of Lemma 3.3(v), the second part of theorem can be proved similarly.

Moreover, from (4.12) we derive

$$
\lim _{i \rightarrow \infty} \sum_{k=0}^{i-1}\left|b_{n k}^{m \lambda}(i)\right|=\sum_{k}\left|b_{n k}^{m \lambda}\right| \leq \sup _{n \in \mathbb{N}} \sum_{k}\left|b_{n k}^{m \lambda}\right| .
$$

If we combine (4.13) and (4.6), we conclude that

$$
\lim _{i \rightarrow \infty} \sum_{k=0}^{i-1}\left|b_{n k}^{m \lambda}(i)\right|
$$

exists for each $n \in \mathbb{N}$. So, condition (4.6) implies condition (4.2).

Theorem 4.4 Given an infinite matrix $A=\left(a_{n k}\right)$ of complex numbers, the following statements hold.

(1) Let $1 \leq p<\infty$. Then $A \in\left(c_{0}^{\lambda}\left(G^{m}\right): \ell_{p}\right)$ if and only if (4.1) and (4.2) hold, and

$$
\begin{aligned}
& \sum_{j=k}^{\infty}\left(-\frac{s}{r}\right)^{n-j}\left[\frac{\left(\begin{array}{c}
m+n-j-2 \\
m-2
\end{array}\right)}{r\left(\lambda_{k}-\lambda_{k-1}\right)}+\frac{\left(\begin{array}{c}
m+n-j-3 \\
m-2
\end{array}\right)}{s\left(\lambda_{k+1}-\lambda_{k}\right)}\right] a_{n j} \text { exists for all } n, k \in \mathbb{N}, \\
& \left\{\frac{\lambda_{k}}{r^{m-1}\left(\lambda_{k}-\lambda_{k-1}\right)} a_{n k}\right\}_{k=0}^{\infty} \in \ell_{\infty} \quad \text { for all } n \in \mathbb{N} .
\end{aligned}
$$

(2) $A \in\left(c_{0}^{\lambda}\left(G^{m}\right): \ell_{\infty}\right)$ if and only if (4.6), (4.14) and (4.15) hold.

Proof From Lemma 3.3(iv) and (v), we know $\left(c_{0}: \ell_{p}\right)=\left(c: \ell_{p}\right)$ and $\left(c_{0}: \ell_{\infty}\right)=\left(c: \ell_{\infty}\right)$. Therefore, the theorem can be proved similarly. 
Theorem 4.5 $A \in\left(c^{\lambda}\left(G^{m}\right): c\right)$ if and only if (4.3), (4.4) and (4.6) hold, and the conditions

$$
\begin{aligned}
& \lim _{n \rightarrow \infty} a_{n}=a, \\
& \lim _{n \rightarrow \infty} b_{n k}^{m \lambda}=\alpha_{k}, \quad \forall k \in \mathbb{N}, \\
& \lim _{n \rightarrow \infty} \sum_{k} b_{n k}^{m \lambda}=\alpha
\end{aligned}
$$

hold.

Proof Given arbitrary $x \in c^{\lambda}\left(G^{m}\right)$, we assume that conditions (4.3), (4.4), (4.6), (4.16), (4.17) and (4.18) hold for an infinite matrix $A=\left(a_{n k}\right)$. We consider Theorem 3.5, and condition (4.6) implies condition (4.2). Then we conclude that $\left\{a_{n k}\right\}_{k \in \mathbb{N}} \in\left\{c^{\lambda}\left(G^{m}\right)\right\}^{\beta}$ for all $n \in \mathbb{N}$, and so $A x$ exists. From (4.6) and (4.17) we have

$$
\sum_{j=0}^{k}\left|\alpha_{j}\right|=\lim _{n \rightarrow \infty} \sum_{j=0}^{k}\left|b_{n j}^{m \lambda}\right| \leq \sup _{n \in \mathbb{N}} \sum_{j}\left|b_{n j}^{m \lambda}\right|<\infty
$$

for all $k \in \mathbb{N}$. This leads us to $\left(\alpha_{k}\right) \in \ell_{1}$, and therefore the series $\sum_{k} \alpha_{k}\left(y_{k}-l\right)$ converges, where $\lim _{k \rightarrow \infty} y_{k}=l$ and so $y \in c$. If we combine Lemma 3.3(iii) with conditions (4.6), (4.17) and (4.18), we deduce that $B^{m \lambda}=\left(b_{n k}^{m \lambda}\right) \in(c: c)$. Also from condition (4.9) we have

$$
A_{n}(x)=\sum_{k} a_{n k} x_{k}=\sum_{k} b_{n k}^{m \lambda} y_{k}+l a_{n} .
$$

With a basic calculation, we obtain

$$
\sum_{k} a_{n k} x_{k}=\sum_{k} b_{n k}^{m \lambda}\left(y_{k}-l\right)+l \sum_{k} b_{n k}^{m \lambda}+l a_{n}
$$

for all $n \in \mathbb{N}$. If we pass to the limit in (4.19), we write

$$
\lim _{n \rightarrow \infty} A_{n}(x)=\sum_{k} \alpha_{k}\left(y_{k}-l\right)+l(\alpha+a)
$$

This shows that $A x \in c$ and so $A \in\left(c^{\lambda}\left(G^{m}\right): c\right)$.

On the contrary, we assume that $A \in\left(c^{\lambda}\left(G^{m}\right): c\right)$. Since every convergent sequence is also bounded, we deduce that $A \in\left(c^{\lambda}\left(G^{m}\right): \ell_{\infty}\right)$. If we consider this fact and Theorem 4.3, we conclude that conditions (4.3), (4.4) and (4.6) hold. Let us take the sequences $h_{(k)}^{m \lambda}(r, s)=\left\{h_{n(k)}^{m \lambda}(r, s)\right\}_{n \in \mathbb{N}} \in c^{\lambda}\left(G^{m}\right)$ and $z=\sum_{k} h_{(k)}^{m \lambda}(r, s)$ defined in Theorem 3.1 and the proof of Theorem 4.3, respectively. Then it is clear that $A h_{(k)}^{m \lambda}(r, s)=\left\{b_{n k}^{m \lambda}\right\}_{n \in \mathbb{N}} \in c$ for every $k \in \mathbb{N}$. Hence condition (4.17) holds. Moreover, from Theorem 2.2 we know that the transformation $L: c^{\lambda}\left(G^{m}\right) \longrightarrow c, L(x)=T^{m \lambda} x$ is continuous. So, we write

$$
T_{n}^{m \lambda}(z)=\sum_{k} T_{n}^{m \lambda}\left(h_{(k)}^{m \lambda}(r, s)\right)=\sum_{k} \delta_{n k}=1
$$


for all $n \in \mathbb{N}$, where

$$
\delta_{n k}= \begin{cases}1, & k=n \\ 0, & k \neq n\end{cases}
$$

This leads us to $T^{m \lambda} z=e \in c$ and so $z \in c^{\lambda}\left(G^{m}\right)$.

It is well known that $c$ is a $B K$-space. If we combine Theorem 2.1 and Lemma 4.1, we conclude that the matrix transformation $A: c^{\lambda}\left(G^{m}\right) \longrightarrow c$ is continuous. Therefore the equality

$$
A_{n}(z)=\sum_{k} A_{n}\left(h_{(k)}^{m \lambda}(r, s)\right)=\sum_{k} b_{n k}^{m \lambda}
$$

holds for all $n \in \mathbb{N}$. This shows that (4.18) holds.

By considering conditions (4.6), (4.17), (4.18) and Lemma 3.3(iii), we deduce that $B^{m \lambda}=$ $\left(b_{n k}^{m \lambda}\right) \in(c: c)$. Hence, (4.3), (4.4) and the last result give us that condition (4.10) holds for all $x \in c^{\lambda}\left(G^{m}\right)$ and $y \in c$. Finally, if we consider $A x, B^{m \lambda} y \in c$ and (4.10), we conclude that condition (4.16) holds. This step completes the proof.

Theorem 4.6 $A \in\left(c^{\lambda}\left(G^{m}\right): c_{0}\right)$ if and only if (4.3), (4.4), (4.6) and the following conditions hold:

$$
\begin{aligned}
& \lim _{n \rightarrow \infty} a_{n}=0, \\
& \lim _{n \rightarrow \infty} b_{n k}^{m \lambda}=0, \quad \forall k \in \mathbb{N}, \\
& \lim _{n \rightarrow \infty} \sum_{k} b_{n k}^{m \lambda}=0 .
\end{aligned}
$$

Proof In Theorem 4.5, if we take Lemma 3.3(vi) instead of Lemma 3.3(iii), the present theorem can be proved by using a similar way.

Theorem 4.7 $A \in\left(c_{0}^{\lambda}\left(G^{m}\right): c\right)$ if and only if (4.6), (4.14), (4.15) and (4.17) hold.

Proof If we combine Lemma 3.3(ii) Theorem 3.5 and Theorem 4.4(2), the present theorem can be proved by using a similar way.

Theorem 4.8 $A \in\left(c_{0}^{\lambda}\left(G^{m}\right): c_{0}\right)$ if and only if (4.6), (4.14), (4.15), (4.20), (4.21) and (4.22) hold.

Proof If we combine Lemma 3.3(vii), Theorem 3.5 and Theorem 4.7, the present theorem can be proved by using a similar way.

Now, by using Lemma 4.2, we give one more result.

Corollary 4.9 Given an infinite matrix $A=\left(a_{n k}\right)$ of complex numbers, we define a matrix $E=\left(e_{n k}\right)$ as follows:

$$
e_{n k}=\frac{1}{\lambda_{n}} \sum_{j=0}^{n}\left(\lambda_{j}-\lambda_{j-1}\right) \sum_{\vartheta=0}^{m-1}\left(\begin{array}{c}
m-1 \\
\vartheta
\end{array}\right) r^{m-\vartheta-1} s^{\vartheta} a_{(j-\vartheta) k}
$$


for all $n, k \in \mathbb{N}$. Then $A$ belongs to matrix classes $\left(c_{0}: c_{0}^{\lambda}\left(G^{m}\right)\right),\left(c: c_{0}^{\lambda}\left(G^{m}\right)\right),\left(\ell_{p}: c_{0}^{\lambda}\left(G^{m}\right)\right)$, $\left(c_{0}: c^{\lambda}\left(G^{m}\right)\right),\left(c: c^{\lambda}\left(G^{m}\right)\right)$ and $\left(\ell_{p}: c^{\lambda}\left(G^{m}\right)\right)$ if and only if E belongs to matrix classes $\left(c_{0}: c_{0}\right)$, $\left(c: c_{0}\right),\left(\ell_{p}: c_{0}\right),\left(c_{0}: c\right),(c: c)$ and $\left(\ell_{p}: c\right)$.

Finally, we put a period to our work by mentioning as of now that the sequence space $f\left(G^{m}\right)$ of almost convergent sequences derived by the domain of $m$ th order generalized difference matrix will be defined and studied analogously in the next paper.

Competing interests

The authors declare that they have no competing interests.

Authors' contributions

The authors read and approved the final manuscript.

\section{Acknowledgements}

We would like to express our thanks to the anonymous reviewers for their valuable comments.

Received: 10 January 2014 Accepted: 4 July 2014 Published: 23 Jul 2014

\section{References}

1. Choudhary, B, Nanda, S: Functional Analysis with Applications. Wiley, New Delhi (1989)

2. Musayev, B, Alp, M: Fonksiyonel Analiz. Balcı Yayınları, Ankara (2000)

3. Wilansky, A: Summability Through Functional Analysis. North-Holland Mathematics Studies, vol. 85. Elsevier, Amsterdam (1984)

4. Wang, C-S: On Nörlund sequence spaces. Tamkang J. Math. 9, 269-274 (1978)

5. Aydın, C, Başar, F: Some new sequence spaces which include the spaces $\ell_{p}$ and $\ell_{\infty}$. Demonstratio Math. 38(3), 641-656 (2005)

6. Aydın, C, Başar, F: On the new sequence spaces which include the spaces co and c. Hokkaido Math. J. 33(2), 383-398 (2004)

7. Malkowsky, E, Savaş, E: Matrix transformations between sequence spaces of generalized weighted means. Appl. Math. Comput. 147, 333-345 (2004)

8. Ng, P-N, Lee, P-Y: Cesàro sequence spaces of non-absolute type. Comment. Math. (Prace Mat.) 20(2), $429-433$ (1978)

9. Altay, B, Başar, F, Mursaleen, M: On the Euler sequence spaces which include the spaces $\ell_{p}$ and $\ell_{\infty}$. I. Inform. Sci. 176(10), 1450-1462 (2006)

10. Malkowsky, E: Recent results in the theory of matrix transformations in sequence spaces. Mat. Vesnik 49, 187-196 (1997)

11. Altay, B, Başar, F: On the paranormed Riesz sequence spaces of non-absolute type. Southeast Asian Bull. Math. 26(5)، 701-715 (2002)

12. Altay, B, Başar, F: Some Euler sequence spaces of non-absolute type. Ukrainian Math. J. 57(1), 1-17 (2005)

13. Şengönül, M, Başar, F: Some new Cesàro sequence spaces of non-absolute type which include the $s p a c e s c_{0}$ and $c$. Soochow J. Math. 31(1), 107-119 (2005)

14. Kızmaz, H: On certain sequence spaces. Canad. Math. Bull. 24(2), 169-176 (1981)

15. Et, M: On some difference sequence spaces. Turkish J. Math. 17, 18-24 (1993)

16. Aydın, C, Başar, F: Some new difference sequence spaces. Appl. Math. Comput. 157(3), 677-693 (2004)

17. Et, M, Çolak, R: On some generalized difference sequence spaces. Soochow J. Math. 21(4), $377-386$ (1995)

18. Ahmad, ZU, Mursaleen: Köthe-Toeplitz duals of some new sequence spaces and their matrix maps. Publ. Inst. Math. (Beograd) 42, 57-61 (1987)

19. Mursaleen, M: Generalized spaces of difference sequences. J. Math. Anal. Appl. 203(3), 738-745 (1996)

20. Asma, Ç, Colak, R: On the Köthe-Toeplitz duals of some generalized sets of difference sequences. Demonstratio Math. 33, 797-803 (2000)

21. Bektas, C: On some new generalized sequence spaces. J. Math. Anal. Appl. 277, 681-688 (2003)

22. Et, M, Başarır, M: On some new generalized difference sequence spaces. Period. Math. Hungar. 35(3), 169-175 (1997)

23. Başarır, M, Kayıkçı, M: On generalized $B^{m}$-Riesz difference sequence space and $\beta$-property. J. Inequal. Appl. 2009, Article ID 385029 (2009)

24. Kirişçi, M, Başar, F: Some new sequence spaces derived by the domain of generalized difference matrix. Comput. Math. Appl. 60(5), 1299-1309 (2010)

25. Sönmez, A: Some new sequence spaces derived by the domain of the triple band matrix. Comput. Math. Appl. 62(2), 641-650 (2011)

26. Malkowsky, E, Parashar, SD: Matrix transformations in space of bounded and convergent sequences of order $m$. Analysis. 17, 87-97 (1997)

27. Malkowsky, E, Mursaleen, M, Suantai, S: The dual spaces of sets of difference sequences of order $m$ and matrix transformations. Acta Math. Sinica (Engl. Ser.) 23(3), 521-532 (2007)

28. Mursaleen, M, Noman, AK: On the spaces of $\lambda$-convergent and bounded sequences. Thai J. Math. 8(2), $311-329$ (2010)

29. Mursaleen, M, Noman, AK: On some new difference sequence spaces of non-absolute type. Math. Comput. Modelling. 52, 603-617 (2010)

30. Sönmez, A, Başar, F: Generalized difference spaces of non-absolute type of convergent and null sequences. Abstr. Appl. Anal. 2012, Article ID 435076 (2012) 
31. Stieglitz, M, Tietz, H: Matrix transformationen von folgenräumen eine ergebnisübersicht. Math. Z. 154, 1-16 (1977)

32. Başar, F, Altay, B: On the space of sequences of $p$-bounded variation and related matrix mappings. Ukrainian Math. J. 55(1), 136-147 (2003)

10.1186/1029-242X-2014-274

Cite this article as: Bişgin and Sönmez: Two new sequence spaces generated by the composition of $m$ th order generalized difference matrix and lambda matrix. Journal of Inequalities and Applications 2014, 2014:274

Submit your manuscript to a SpringerOpen ${ }^{\circ}$ journal and benefit from:

- Convenient online submission

- Rigorous peer review

- Immediate publication on acceptance

Open access: articles freely available online

- High visibility within the field

- Retaining the copyright to your article

Submit your next manuscript at $\gg$ springeropen.com 